DOI 10.37882/2223-2982.2020.07-2.26 \title{
ФОРМИРОВАНИЕ МЕЖКУЛЬТУРНОЙ КОМПЕТЕНЦИИ У СТУДЕНТОВ В УСЛОВИЯХ ДИСТАНЦИОННОГО ОБУЧЕНИЯ
}

\section{THE INTER-CULTURAL COMPETENCE FORMATION FOR STUDENTS IN DISTANCE LEARNING}

\section{Nikolaeva \\ E. Suslennikova}

Summary: The article is devoted to the formation of intercultural competence among students at Russian universities in the conditions of distance learning (for example, teaching foreign languages). The relevance of the research topic is due to the fact that during the use of distance learning in quarantine on COVID-19, practice teachers were forced to reconsider their critical attitude to the distance learning possibilities. The article goal is to consider the advantages and disadvantages of distance learning from the point of view of the formation of intercultural competence. The methodology of the article is based on a communicative approach and includes a group of general scientific methods (analysis, synthesis, induction, deduction); as well as special methods: a content analysis of scientific literature on the topic of research, a comparative analysis method. Based on the results of the study, the author of the article came to the following conclusions: assessing the effectiveness of distance learning methods in the Russian higher education system requires empirical verification after the first mass application in the 2020 academic year; remote methods and tools have both advantages and disadvantages that need to be leveled in the learning process; in the future, the use of distance learning for the formation and development of intercultural competence of students requires the development of systematic methodological foundations.

Keywords: distance education, online education, intercultural competence, linguistic culture, communicative approach.

\author{
Николаева Мария Владимировна \\ старший преподаватель, Московский Авиационный \\ Институт им. С. Орджоникидзе, г. Москва, \\ marianick@inbox.ru \\ Сусленникова Елена Эдуардовна \\ старший преподаватель, Московский Авиационный \\ Институт им. С. Орджоникидзе, г. Москва
}

Аннотация: Статья посвящена проблематике формирования межкультурной компетенции у студентов российских вузов в условиях дистанционного обучения (на примере преподавания иностранных языков). Актуальность темы исследования обусловлена тем, что в период использования дистанционного обучения в условиях карантина по COVID-19 преподаватели-практики были вынуждены пересмотреть свое критическое отношение к возможностям дистанционного обучения. Цель статьи заключается в рассмотрении преимуществ и недостатков средств дистанционного обучения с точки зрения формирования межкультурной компетенции. Методология статьи основана на коммуникативном подходе и включает в себя группу общенаучных методов (анализ, синтез, индукция, дедукция); а также специальные методы: контент-анализ научной литературы по теме исследования, метод сравнительного анализа. По итогам проведенного исследования автор статьи пришел к следующим выводам: оценка эффективности методов и средств дистанционного обучения в условиях российской системы высшего образования требует эмпирической верификации после первого массового применения в 2020 учебном году; методы и средства дистанционного обучения имеют как преимущества, так и недостатки, которые необходимо нивелировать; в дальнейшем применение дистанционного обучения для формирования и развития межкультурной компетенции студентов требует разработки системных методологических основ.

Ключевые слова: дистанционное образование, онлайн-обучение, межкультурная компетенция, лингвокультура, коммуникативный подход.
A ктуальность темы исследования обусловлена тем, что в условиях пандемии COVID-19, в российской практике преподавания иностранных языков произошел пересмотр возможностей дистанционного обучения в высших учебных заведениях. В классической академической системе высшего образования в России довольно долгое время дистанционное обучение рассматривалось как вторичное направление, которое использовалось в основном в рамках инклюзивного и дополнительного образования. В научном сообществе существовало критическое отношение к возможностям дистанционного обучения. Сторонники традиционной системы высшего образования полагали, что дистанционные методы обучения могут служить только как дополнительные, но не основные [3; 4]. Тем не менее, в ситуации пандемии и при переходе всех российских вузов на дистанционную систему обучения, преподавателипрактики и исследователи-теоретики вынуждены были пересмотреть свое отношение к эффективности средств дистанционного обучения [6, с. 88].

Одной из насущных проблем в процессе обучения иностранным языкам в условиях пандемии стали те средства дистанционного обучения, которые позволяют формировать и развивать межкультурную компетенцию у студентов.

Согласно ФГОС «+++» для бакалавриата, межкультурная компетенция представляет собой конечный результат обучения иностранным языкам в вузе: «межкультурная компетенция - это способность эффективно общаться с представителями разных культур и наци- 
ональностей» [6, с. 89], то есть изучение иностранных языков в вузе служит обеспечению межкультурного общения в различных профессиональных сферах с представителями иностранных культур. Данное требование ФГОС невозможно реализовать без создания языковой среды и изучения иностранной культуры, что требует наличия живого диалога между представителями различных лингвокультур. Поэтому научное обсуждение возможностей формирования межкультурной компетенции в рамках формата дистанционного обучения приобретает особую актуальность.

Тем не менее, несмотря на обширную историографию вопросов, связанных с дистанционным обучением как таковым, а также с проблемами формирования межкультурной компетенции у студентов, в настоящее время существует достаточно мало исследований, посвященных проблеме применения средств дистанционного обучения для формирования межкультурной компетенции.

Отчасти данный историографический пробел объясняется тем, что программы дистанционного обучения ранее разрабатывались только для дополнительного и инклюзивного образования в вузе, а также тем, что детальная оценка результативности дистанционного обучения в целом в России в период пандемии COVID-19 пока не проводилась.

Однако, по проблематике исследования можно выделить ряд работ, в которых рассматривается вопрос эффективности дистанционного обучения в преподавании иностранных языков. К таким исследованиям, в частности, относятся работы А.В. Агеевой [3], Т.В. Амосовой [2]. С тезисами данных авторов солидарны также такие зарубежные авторы, как: М. Оловария и К. Карпио [10], работы которых посвящены вопросам эффективности средств и методов дистанционного обучения в вузе.

Также, в своей работе Н.А. Каменева и Л.В. Зенина отмечают, что разработка новых информационных технологий и их внедрение в образовательный процесс для передачи знаний и компетенций является неотъемлемой частью нашего времени [7, с. 3]. Информационные и коммуникационные технологии являются эффективными средствами, методами и техниками для решения основных проблем и достижения целей образования. Изучение иностранных языков как компонента гуманизации высшего образования имеет большое значение, поскольку оно способствует формированию целостного взгляда на мир, воспитанию ценностей, построению коммуникативных связей, отношений и взаимопонимания между разными людьми, нациями и культурами. Современные информационные и коммуникационные технологии играют неоценимую роль в этом процессе [7, c. 3].
По мнению исследователей, в ходе преподавания иностранных языков информационные технологии меняют социальное и коммуникационное пространство, тем самым создавая новые условия для развития эвристического диалога между носителями разных языковых культур [7, с. 3]. Некоторые преподаватели-практики отмечают также, что в процессе формирования межкультурной компетенции студентов особую роль может играть интернет-коммуникация, поскольку она имеет достаточно разнообразные форматы: веб-форум, аудиовидео конференции, чат, блог, электронная почта, онлайн-обмен файлами и т. д. [9, с. 19].

Таким образом, в целом интернет предоставляет реальные возможности для моделирования учебной и информационной среды, с определенными коммуникационными связями и отношениями. Дистанционное обучение позволяет решить также одну важную, на наш взгляд, проблему: наладить межкультурный диалог между носителями языка в режиме реального времени, то есть коммуникация в таком формате обучения имеет трансграничный характер. В формате дистанционного обучения студенты имеют возможность живого общения с носителями языка, причем в учебном процессе такая межкультурная коммуникация возможна с использованием достаточно обширного набора средств преподавания, в том числе - с использованием вебинаров, видеоклипов, аудио-скриптов, форумов, диаграмм, ICQ, Skype, онлайн-тестирования, интерактивных учебников и досок $[9$, с. 19].

С точки зрения формирования межкультурной компетенции средства дистанционного обучения можно разделить на две большие группы:

1. инструменты синхронного обучения: чаты, ICQ, Skype, интерактивные доски, видеоконференции;

2. инструменты асинхронного обучения: электронная почта, блоги, форумы, Twitter, видео- и аудиоподкасты, онлайн-тестирование.

Асинхронный характер сетевых коммуникаций позволяет пользователям участвовать в диалоге, форуме или вебинаре в любое удобное время, независимо от времени или местоположения.

При этом, существует множество преимуществ и недостатков как в синхронных, так и в асинхронных средствах электронного обучения, а также в специфике передачи данных.

Преимущества онлайн-инструментов синхронной связи, по мнению исследователей, заключается в том, что такая связь полезна для поддержки личных контактов со студентами. Также эта группа средств дистанционного обучения дает ощущение прямого голосового 
контакта как между преподавателями и студентами, так и между студентами и носителями языка. Онлайн-связь позволяет также сохранять спонтанность и беглость речи, максимально приближая учебную среду к реальным языковым условиям коммуникации.

Онлайн-средства асинхронной связи также имеют свои преимущества при формировании и развитии межкультурной компетенции:

1. Время и возможность обдумать ответ для успешной коммуникации с носителями языка;

2. Возможность полноценного участия в процессе общения в любое время;

3. Данная группа средств дистанционного обучения также позволяет менять скорость речи, чтобы студенты с различными языковыми навыками могли быть легко вовлечены в учебный процесс;

4. Возможность использования каналов связи с низкой пропускной способностью;

5. Участники взаимодействия не зависят от времени, места и процесса планирования занятий;

6. Определенный комфорт при общении в письменной форме [7, с. 4].

Однако, в процессе применения модели дистанционного обучения для всех категорий студентов в условиях режима самоизоляции, помимо преимуществ данного формата преподавания иностранных языков, были выявлены также и недостатки. В частности, к недостаткам использования интерактивных средств синхронной связи большинство исследователей относят крайне слабую технологическую базу, которая не была рассчитана на процесс дистанционного обучения для всех категорий студентов и часовых планов занятий [6].

При этом на некоторых цифровых платформах, в которых возможно непрерывное дистанционное обучения, в частности, Google Class, проявился недостаток, связанный с максимально допустимым количеством участников в онлайн-занятиях. То есть за время карантинных мер и дистанционного обучения студентов во многих вузах, особенно в провинциальных, проявилась нехватка дополнительного аппаратного и программного обеспечения, поскольку потоковое дистанционное обучение требует каналов с более высокой пропускной способностью для аудио- и видеоконференций. Недостатки онлайн-средств асинхронной коммуникации проявились в нехватке личного контакта и устной коммуникации; а также в том, что обратная связь может быть отложена на несколько дней или часов [6].

В силу перечисленных недостатков двух типов связи, российскими преподавателями иностранных языков в условиях дистанционного обучения использовался в основном такое интерактивное средство, как вебинар, ко- торый можно отнести к обеим категориям: синхронному и асинхронному типу связи. В случае участия студентов в онлайн-вебинаре и прослушивания лекции преподавателя в режиме реального времени, такой формат связан именно с синхронным обучением. Если запись вебинара была загружена студентами с сайта университета некоторое время назад, в этом случае можно говорить об асинхронном типе вебинара как средства дистанционного обучения.

С позиции преподавания иностранных языков с целью формирования межкультурной компетенции, именно вебинар является наиболее эффективным, поскольку студенты могут зарегистрироваться на участие в вебинаре или посмотреть его запись, если они не могут участвовать в нем в режиме реального времени.

Вторым по уровню эффективности средством дистанционного обучения, позволяющим реализовать задачи формирования и развития межкультурной компетенции, преподаватели-практики считают видеоконференцсвязь [6].

С помощью инструментов видеоконференцсвязи, таких как mailVU и Skype, студенты могут загрузить план занятия, методические и учебные материалы, а также самостоятельно сделать видеозапись.

В настоящее время видеоконференцсвязь как средство улучшения коммуникации является предметом обсуждения в экспериментальных и научных исследованиях, посвященных проблематике дистанционного обучения [10, с. 85]. Поскольку межкультурная компетенция является неотъемлемым элементом коммуникативной компетенции, то в процессе преподавания иностранных языков необходимо использовать все возможности видеоконференцсвязи для создания адекватной лингвокультурной среды общения.

Видеоконференцсвязь в образовательных целях обычно создает такую ситуацию, при которой студенты имеют возможность не только сформулировать свои собственные мысли на иностранном языке, но также выслушать мнение друг друга и сравнить свои точки зрения.

Таким образом, дальнейшее развитие дистанционного образования означает структурированную среду обучения, которая объединяет аудио- и видеоконференции, текстовый чат, интерактивные доски, приложения на цифровых устройствах, инструменты тестирования и обратной связи, форумы и вебинары.

В итоге процесс дистанционного обучения должен происходить с помощью комбинации синхронных и 
асинхронных средств связи, сохраняя при этом гибкость графика и удобство, а также повышая качество и эффективность обоих способов коммуникации. При этом, в дистанционном формате обучения, которое имеет межкультурный характер, преподаватель, безусловно, должен принимать во внимание специфику языковых средств и ресурсов, технологические особенности, которые могут не только способствовать лингвокультурному диалогу, но и усложнять задачу формирования межкультурной компетенции.

В период потокового дистанционного обучения в условиях режима самоизоляции преподаватели иностранных языков столкнулись как с методологическими, так и с дидактическими задачами, направленными на формирования межкультурной компетенции, которая определяется способностью вести диалог с собеседниками, формулировать свои мысли, определять задачи коммуникации, «избегать двусмысленности сообщений, и т.п.» [10, с. 89]. При этом, в научно-педагогическом сообществе вновь возник вопрос о том, насколько допустимо использование электронных словарей и онлайн-переводчиков в процессе обучения иностранным языкам. Если в реальной аудитории преподаватель может настаивать на использовании печатных словарей, то в дистанционном формате обучения этот момент невозможно контролировать.

При рассмотрении результатов внедрения электронных словарей в учебный процесс выяснилось, что студенты предпочитают использовать портативные электронные словари, а для перевода оригинальных текстов используют онлайн-переводчик [9, с. 22]. Как правило, качество такой работы низкое и не соответствует требуемым стандартам перевода, а также препятствует самостоятельному запоминанию новых лексических единиц [9, с. 23].

Для формирования межкультурной компетенции в условиях дистанционного обучения необходим активный и широкий словарный запас, а не электронное калькирование стандартного набора фраз и речевых оборотов. Использование аутентичных словарей, позволяет активировать не только механическую, но и зрительную память [10]. Поэтому студентов необходимо мотивировать к использованию электронных оффлайн-словарей с помощью комплекса конкретных упражнений и проектных видов деятельности. Такого рода электронные словари и электронные версии печатных словарей в настоящее время широко доступны на рынке программного обеспечения и печатной продукции. Таким образом, электронные словари должны играть важную роль в процессе дистанционного обучения студентов в университете.
В условиях дистанционного обучения российским преподавателями вузов широко использовался также так формат, как блог: дискуссионный или информационный сайт, публикуемый в Интернет и состоящий из отдельных записей («сообщений»), обычно отображаемых в обратном хронологическом порядке. В формате дистанционного обучения личный блог позволяет каждому студенту иметь свой собственный веб-журнал. Эти блоги доступны для просмотра всей группе или только преподавателю, причем посетители блога могут также размещать там свои публикации или комментарии.

Тематический (групповой) блог - это пространство для совместной работы, где студенты и преподаватели могут обмениваться идеями при обсуждении общей темы. Использование этой функции ограничено только воображением преподавателя. Данный формат очень удобен в силу того, что преподаватель контролирует весь доступ к тематическому блогу.

Блог заданий - новая функция, которая позволяет преподавателям публиковать задания для студентов, а затем оценивать их в конфиденциальной обстановке. Студенты могут работать над заданиями в нескольких онлайн-сессиях, а затем отправлять их по мере готовности. Преподаватели могут впоследствии оценить или вернуть задание студенту для дальнейшей работы.

С точки зрения формирования и развития межкультурной компетенции формат блога очень ценен, поскольку дает возможность продлить время прохождения курса; а также позволяет каждому студенту принимать активное участие в процессе общения на иностранном языке, и в то же время -реализовывать принцип индивидуального подхода к образованию.

По мнению преподавателей-практиков, в процессе работы со студентами блог позволяет формировать компетенции в следующих областях: понимание на слух иностранного языка аутентичного материала; письменная речь на иностранном языке; создание и ведение блога на иностранном языке; поиск информации по заданной теме на иностранном языке; анализ проделанной работы и формирование самооценки на иностранном языке.

Если набор средств дистанционного образования в условиях вуза широк, но все-таки ограничен, то методы преподавания иностранных языков в дистанционном формате практически неисчерпаемы. В частности, сторонники коммуникативного подхода к обучению иностранным языкам полагают, что студенты учатся лучше и быстрее, если используемые методы обучения соответствуют их индивидуальным стилям обучения. При этом, в рамках дистанционного обучения отношения между студентами и преподавателями могут быть радикально 
изменены, поскольку студенты более активно вовлекаются в учебный процесс и становятся более заинтересованными в понимании культуры страны изучаемого языка [10, с. 88].

Таким образом, можно сделать вывод о том, что вынужденный карантин в высших учебных заведениях в связи с COVID-19 и переход на всеобщее дистанционное обучение в третьем семестре 2020 учебного года, позволил пересмотреть взгляды научно-педагогического сообщества на возможности дистанционного обучения практически во всех областях знаний. При этом, в преподавании иностранного языка с целью формирования межкультурной компетенции, возможности дистанцион- ного обучения практически не ограничены с методологической точки зрения.

Следует подчеркнуть, что использование современных информационных технологий может повысить мотивацию студентов к обучению, их ответственность, уровень самореализации, а также сформировать навыки общения и межкультурную компетентность. В этой связи перспективным представляется проведение серии эмпирических исследований по вопросу эффективности средств и методов дистанционного обучения при реализации задачи формирования межкультурной компетенции у студентов российских вузов.

\section{ЛИТЕРАТУРА}

1. Агеева, А.В. Проблема формирования межкультурной компетенции / А.В. Агеева // Инновационная наука. - 2015. - № 6. - С. 185 - 188.

2. Амосова, Т.В. Содержание иноязычной профессионально-коммуникативной компетенции в федеральном государственном образовательном стандарте / Т.В. Амосова // Образование. Наука. Научные кадры. - 2019. - № 1. - С. 117 - 122.

3. Бронзова, Л.И. Обучение иностранному языку в системе дистанционного образования / Л.И. Бронзова // Известия Тульского государственного университета. - Гуманитарные науки. - 2012. - № 2. - С. 1 - 6.

4. Девтерова, 3.Р. Проблемы дистанционного обучения иностранным языкам в вузе / З.Р. Девтерова // Вестник Университета Российской академии образования. - 2011. - № 2. - С. $4-10$.

5. Каменева, Н.А. Дистанционное обучение иностранным языкам / Н.А. Каменева // Мир науки. Педагогика и психология. - 2015. - № 3. - С. 1 - 9.

6. Пригожина, К.Б. Развитие качеств мультикультурной личности как залог сформированности межкультурной компетенции / К.Б. Пригожина // Вестник Московского государственного лингвистического университета. Образование и педагогические науки. - 2020. - №1. - С. 88 - 100.

7. Kameneva, N.A. (2013) Distance learning for developing knowledge and skills in English language teaching / N.A. Kameneva, L.V. Zenina // Economics, Statistics and Informatics. - Vol. 5. - Pp. $3-6$.

8. Mauricio, 0.-G. (2020) Distance learning and universities / 0.-G. Mauricio, C. Carpio // University of Santiago, Chile. - 2020. - 220 p.

9. Pyshnohub, M. (2020) Technology of successful distance learning at the university / M. Pyshnohub // Conference: les tendances actuelles de la mondialization de la science Mondale. - Vol.2. - Pp. 19-25. D0l: 10.36074/03.04.2020.v2.19

10. Tajiev, M. (2020) Features of Distance Learning Technology / M. Tajiev // International Journal of Psychosocial Rehabilitation. - Vol.5. - Pp. 84 - 92. D0I: 10.37200/ IJPR/V24I5/PR2020574ISBN: 1475-7192

(с) Николаева Мария Владимировна (marianick@inbox.ru), Сусленникова Елена Эдуардовна.

Журнал «Современная наука: актуальные проблемы теории и практики» 